\title{
Duplo E IDENTIFICAÇÃO NA ADOLESCÊNCIA: A PROPÓSITO DE UM CASO
}

\author{
Férodja Hocini* \\ Tradução de Bianca Novaes**
}

\section{RESUMO}

A autora explora os processos de identificação que atuam na constituição do sujeito. Através de um caso clínico, são abordados os mecanismos inconscientes em jogo no que Freud denominava de "apropriação" das qualidades e características do outro. Por meio da investigação do tema do duplo na adolescência, a autora chega às origens inconscientes do processo de identificação, desvelando a relevância das fantasias ancestrais, ou seja, de elementos identificatórios inconscientes que são transmitidos de geração a geração e que atuam no processo de identificação de cada sujeito. No estudo do caso clínico, ela se defronta com os fantasmas inconscientes ancestrais que conduzem a essa identificação, reunindo a história familiar e os acontecimentos vividos pelo sujeito.

Palavras-chaves: adolescência, duplo, identificação, subjetivação

\section{Abstract}

DOUBLE AND IDENTIFICATION IN ADOLESCENCE: A CLINICAL CASE

The author explores the identification processes that operate in the constitution of the subject. Through a clinical case, the unconscious mechanisms involved in what Freud called the "appropriation" of the qualities and characteristics of the other are presented. Discussing the theme of the double in adolescence, the author arrives at the unconscious origins of the identification process, displaying the relevance of the ancestral phantoms, that is, of unconscious identificatory elements that are transmitted from generation to generation and that take place in the process of identification of each human being. In the study of the clinical case, she faces

* Psicanalista; Responsável pelos cursos "Psicose e estados-limites" na Escola Doutoral "Pesquisas em Psicopatologia e Psicanálise”, Universidade Paris 7 - Denis Diderot.

** Doutoranda em Psicologia Clínica (PUC-Rio). 
the unconscious ancestral fantasies that lead to this identification, congregating familiar history and the events lived by the subject.

Keywords: adolescence, double, identification, subjectivity

Amélie está com 18 anos quando eu a encontro para uma psicoterapia. Ela me procura por recomendação de um colega psiquiatra em conseqüência de uma terceira hospitalização após uma tentativa de suicídio através de medicamentos.

Segundo seus termos, ela “já esgotou vários psicoterapeutas”, interrompendo de repente, ora impulsivamente após algumas sessões, ora após uma interpretação "que ultrapassava os limites”. Há dois anos, ela consulta seu psiquiatra uma vez por semana para tratamento médico de perturbações de condutas alimentares e depressivas que evoluem há vários anos. A aparência física de Amélie - pequena morena magrela de óculos redondos e de caminhar inseguro - contrasta, imediatamente, com a violência com a qual ela se exprime. Ela tenta dissimular seu corpo por detrás de um jeans bastante largo e de blusões, cuja amplidão mascara facilmente toda forma feminina (da qual é-se levado, aliás, a interrogar a existência).

Segundo Amélie, "tudo começou" aos 15 anos, após o falecimento de sua melhor amiga, Angèle, em conseqüência de uma leucemia que evoluía desde a idade de 7 anos. Essa bela amizade, como é comum nas grandes histórias, tinha começado, entretanto, por acaso - se recorda, com malícia, Amélie. No primeiro ano do curso preparatório, na escola primária, a professora as tinha colocado uma ao lado da outra, nas primeiras fileiras, pois as duas usavam óculos. Nada, então, as predispunha, segundo ela, a se tornarem "as melhores amigas do mundo". Ela é morena, vinda de uma família de quatro crianças, de origem modesta; Angèle era filha única de um casal de ricos empresários. Angèle tinha um ano a mais, ela era muito bonita com seus cachos loiros que caíam sobre seus ombros - se lembra Amélie com o olhar longínquo... Eu imagino a moça tal como ela me descreve, ela se assemelhava a um anjo, Angèle, Ange e Elle [anjo e ela], as duas em uma única... $\operatorname{alma}(s) \operatorname{irmãa}(s)$.

Amélie, desde o início da doença de Angèle, sempre esteve ao seu lado, sempre fiel, levando sua pasta à escola, trazendo seus deveres para sua casa, seguindoa como sua sombra. Amélie pensava saber tudo o que sua amiga sentia, "como irmãs gêmeas", afirma ela com segurança. Sem temer a contradição, ela acrescenta que tinha um interesse particular em não mostrar nada do que podia sentir.

Aliás, o que ela sentia? Impossível para Amélie responder a essa questão, ela não pensava, ela "era", ela "agia", "isso é tudo". 
O que seus pais diziam disso? Eles a apoiavam nos cuidados com Angèle.

Mesmo assim, isso devia ser terrível, não? "Como se lamentar, quando se pensa em tudo o que Angèle suportava...”, acena ela, secamente, levantando os ombros com um ar de evidência e provocação.

Durante esses oito anos, Amélie passa então muito tempo com sua amiga, na escola e durante seus lazeres, mesmo durante as férias escolares, e também durante a visita nas numerosas hospitalizações ligadas a essa grave hemopatia.

A notícia do falecimento de Angèle "é o fim de tudo". Amélie se fecha durante duas semanas em um mutismo do qual ela dirá, mais tarde, que "era uma greve da palavra”. Uma anorexia mental se instala um pouco após esse período. Ao mesmo tempo, ela apresenta um eczema cutâneo e uma pelada, acarretando depilação de placas inteiras do couro cabeludo e coceiras no corpo todo, traços que, certamente, lembram os que provavelmente marcaram o corpo de Angèle durante sua longa doença, no curso dos tratamentos pesados que ela pode ter sofrido (principalmente, os efeitos alopeciantes das quimioterapias, as alternâncias iatrogênicas de fases de emagrecimento e de ganho de peso).

Amélie descreve, então, sua vida como "um deserto sem nome"; diz-se invadida por um sentimento de vazio e de angústia diante da idéia de "se vincular a uma pessoa por medo de vê-la morrer”. Ela evoca uma série infernal de separações e de lutos, particularmente a morte de seu clínico geral, de quem ela era próxima, ocorrida brutalmente em um acidente de automóvel, ou, ainda, o suicídio de um amigo da família; enfim, toda uma lista macabra onde se esboça uma certa onipotência de seu discurso. Amélie explica que está "vinculada ao seu psiquiatra". Toda despedida ou substituição de um encontro traz, então, temas não apenas de angústia de separação, mas também de angústia de "desaparecimento" no vazio deixado pela ausência. Ela, aliás, decidiu se organizar para ser hospitalizada sistematicamente na clínica psiquiátrica durante cada período de férias escolares, como se fosse para permanecer protegida ou contida.

No momento em que encontro Amélie, a anorexia deu lugar a condutas bulímicas e as lesões dermatológicas, a gestos automutilatórios, ou, ainda, a repetidas tentativas de suicídio através de medicamentos, nas quais ela diz ora buscar morrer, ora buscar repouso em um coma que faria "suspender o tempo ao mesmo tempo que o sofrimento e a angústia”. Assim, a angústia é aqui bastante característica, invasiva, ineficaz do ponto de vista econômico, somente deixando como recurso para a paciente a passagem ao ato impulsivo, impedindo qualquer acesso a uma verbalização e a uma elaboração. Apesar da crítica secundária aos gestos automutilatórios, eles se repetem segundo o mesmo "ritual", parecendo dar à paciente o sentimento de existir ao experimentar a dor na forma de reificação do 
corpo. Com efeito, pelas escarificações, tudo se passa como se o sujeito experimentasse os limites da pele como continente e tentasse, assim, evacuar a angústia, tal como um líquido que bastasse fazer surgir ou derramar. Assim, o termo "solução de contituidade" poderia encontrar aqui toda a sua ressonância.

Para ela, é difícil falar do passado, considerar perspectivas (quer seja no tempo ou no espaço), tudo parece se inscrever em um "aqui e agora”. De sua infância ela diz que foi feliz apenas enquanto Angèle estava viva, que não há nada a saber além disso. Em nenhum momento, chega a evocar o que ela pôde sentir ao lado de sua amiga gravemente doente, argumentando "que era assim mesmo". Amélie fala, aliás, poucas coisas de sua relação com seus pais. Ela diz ter tido sempre boas relações com eles, o que quer dizer que não houve nenhum momento de revolta adolescente. Ao se interrogar sobre algum movimento adolescente, vê-se que nenhum vento pubertário parece ter soprado sobre esse corpo tão pouco marcado pela sexualidade.

Faz apenas dois anos que nós começamos essa psicoterapia, matizada por momentos de ruptura devidos, às vezes, a hospitalizações (programadas por ela ou secundárias às passagens aos atos suicidas), às vezes, a interrupções voluntárias de sua parte, em ocasiōes em que ela se desespera face à ausência de progresso e de mudanças em sua vida, desvalorizando o processo psicoterápico (com o qual ela chega, entretanto, a manter alguns laços). As tendências à transgressão do quadro, verdadeiras modalidades transferenciais, sobrevêm regularmente. Períodos muito difíceis já percorreram essa terapia: múltiplas tentativas de suicídio e pedidos de socorro deixados na secretária eletrônica me levavam a intervir em urgência.

As conversas são interrompidas por pedidos de explicações de preferência à interpretação e à busca de sentido; elas são marcadas por uma dificuldade de acesso à atividade simbólica e, muito freqüentemente, pela negação e pela clivagem. As lembranças são difíceis de mobilizar, pois o tempo parece inscrever-se no imediatismo (do vivido instantâneo, do que é sentido, do ato), sem jamais poder desenvolver-se no fio de uma história. Desse tipo de imobilidade psíquica parece emanar uma queixa que, freqüentemente e com muita resistência, recusa qualquer deslocamento, qualquer idéia de um jogo possível, qualquer interpretação. A atividade de devaneio é rara, para não dizer quase inexistente, deixando lugar a propósitos factuais que deixam um espaço tão reduzido às associações que, por vezes, se tem a impressão de que há um bloqueio do pensamento. No curso dessa terapia sobreveio um acontecimento raríssimo em minha experiência clínica: eu sonhei com essa paciente que, no sonho, me empurrava violentamente pelos ombros colocação em cena de um corpo a corpo violento ou de um fantasma erótico que 
figurava as angústias de intrusão sentidas pela paciente diante do insustentável da identificação projetiva e que remetia ao impossível da representação do luto por seu duplo (a morte de Angèle ?...).

Recentemente, a paciente deixa, de tempos em tempos, na caixa de correios do consultório, cartas (que não esperam, evidentemente, resposta) - uma maneira que a paciente encontrou de endereçar-se ao ausente, ou de tentar inscrever-se como sujeito pelo nascimento da escritura endereçada ao outro.

Segundo André Green (1990), não se trata tanto, para a paciente, de colocar, de imediato, um fracasso em toda tentativa de pedido de socorro ou de verbalização, mas da própria impossibilidade de pensar esse apelo. Todo o ódio que freqüentemente emerge em seu discurso parece refletir um compromisso entre um desejo inextinguível de vingança e o cuidado de proteger o objeto dos desejos hostis dirigidos contra ele. Esse desejo de vingança nasceu de uma ferida que atingiu severamente seu narcisismo. Para o autor, esses sujeitos visam perpetuar, por tanto tempo quanto possível, a situação em que encontram um parceiro que aceita desempenhar o papel que eles lhe atribuem, ou seja, a forma de relação que elegeram. A resposta a essa lógica do desespero não consiste em confortar o paciente lhe apresentando a perspectiva de uma esperança possível que, assim que formulada, seria reduzida, inexoravelmente, ao nada. Não consiste tampouco em se deixar arrastar pelo paciente no desespero. $\mathrm{O}$ que se pode fazer é mostrar ao paciente como tem a necessidade de criar o desespero no analista, assim como quer poder verificar se o analista pode sobreviver a esse ódio e continuar exercendo sua função (Green, 1990).

Segundo Amélie, o início das perturbações remonta à adolescência, no momento da morte de sua amiga de infância, momento em que lhe pareceu que ela perdia a metade de si mesma. Isso foi, então, para ela, segundo suas palavras, a "catástrofe de [sua] vida". Contudo, é muito provável que as perturbações sejam mais antigas, a catástrofe já havia sobrevindo desde muito tempo. Do ponto de vista psicopatológico, a questão do duplo no processo de identificação, tal como define Piera Aulagnier (1984), parece aqui inteiramente operante. A autora evoca o duplo como uma prótese identificatória que vem amenizar as falhas do processo identificatório faltoso da criança. A “descompensação" de Amélie após o falecimento de seu duplo ocorreu porque esse acontecimento psíquico apenas desvelou uma catástrofe identificatória que já havia tido lugar. A adolescente jamais havia encontrado, em seu percurso identificatório passado, as condiçôes que lhe teriam assegurado o caráter autônomo de suas marcas identificatórias no registro simbólico (lembremos que o primeiro sintoma que ela descreve é uma "greve da palavra"), marcas que lhe teriam permitido uma certa liberdade na escolha de seus 
objetos, de seus desejos também, lhe permitindo, então, experimentar o que Winnicott (1969) chama de continuidade de existir.

O modo de relação dessa amizade não tinha nada em comum, vimos, com as amizades que as crianças geralmente nutrem. Esse modo de relação, no mínimo fusional, que ela mantinha com Angèle era "já” não uma causa, mas uma conseqüência dessa catástrofe primeira, sinal, em todo caso, de uma organização patológica nos processos de identificação dessa criança. Durante a infância e, mais particurlamente ainda, durante a adolescência, é muito comum que as primeiras relações afetivas com os outros se estabeleçam com os do mesmo sexo. Esse tempo de cumplicidade com o amigo do coração com quem se partilha tudo, como lembra Serge Lesourd (2002), é um tempo de reassegurar o narcisismo necessário para o adolescente. O outro, o cúmplice, deve ser pouco dessemelhante de si para que o narcisismo ainda frágil do adolescente não seja mal sucedido por uma diferença excessivamente importante. $\mathrm{O}$ outro, enquanto objeto de amor, deve, primeiramente, ser semelhante a si para que permaneça o objeto de amor principal, pois é pela transferência do amor de si para o outro que o adolescente investe a relação com o outro semelhante. As relações de amizade na adolescência inscrevem-se, assim, sob a figura do duplo, do sósia, tão bem descrita por Otto Rank ([1932] 1990). Nessas relações, o objeto de amor deve ser o duplo narcísico confortador do adolescente, quer seja nas relaçóes de amizade e afetivas, ou nas relações sensuais e eróticas. As relações homossexuais transitórias não são raras nessa época, são elas que permitem ao adolescente descobrir a relação sensual com um outro, diferente de si e, entretanto, idêntico. São verdadeiras relações amorosas com o duplo (Lauru, 2001). A violência das rupturas é, então, inelutável, pois essa traição do outro, que encontra um outro objeto de amor, remete àquilo que é sua falha narcísica. É então que desponta a violência do ódio que substitui a cumplicidade narcísica, violência do ódio que é sempre o duplo em negativo dessa paixão centrada sobre si. Era todo esse ódio que se podia ouvir em Amélie, ódio do outro, da vida que lhe tinha retirado o que havia de mais querido no mundo.

Os pais de Amélie, em uma entrevista com ela, tinham confirmado os dizeres da paciente (ou, antes, os não-ditos), negando a potencialidade violenta e angustiante que podia comportar uma tal situação: “mesmo assim, não adiantava ficar falando disso todos os dias, aliás, nunca falávamos disso, tudo ocorria naturalmente". Causava espanto ouvir esses pais, que tinham encorajado sua filha a se dedicar a uma criança gravemente doente sem buscar protegê-la, sem nem mesmo buscar colocar em palavras o que ela teria podido sentir de temor, de angústia, e de ódio também. No curso das entrevistas com a família, pôde-se, enfim, reconstruir a história (e uma pré-história) familiar(es); descobriu-se, assim, a desgraça de 
um bisavô entregue à sua demência, totalmente abandonado pela família que deixava então a África do Norte, com o pouco de bagagem que levavam, pesada de remorsos e de tristeza. Então, que laços estabelecer entre essa culpabilidade inconsciente trazida através de gerações e o sacrifício carregado de reparações a que se entregava Amélie, sob o altar da dívida familiar?

Os fantasmas da identificação são, por definição, inconscientes. A identificação, para Freud, não é, portanto, uma simples imitação, mas antes uma apropriação (Aneignung) sobre a base de uma mesma pretensão etiológica; ela deriva de um elemento comum que persiste no inconsciente (Freud, 1925). Amélie, que não tinha nenhum conhecimento (pelo menos consciente) dessa parte da história familiar, parecia, com efeito, ter efetuado essa "incorporação" inconsciente. Talvez, a sombra desse antepassado voltasse assim, por esse viés, a se perfilar novamente na atualidade familiar. Nicolas Abraham (1978) mostrou que o fantasma é o trabalho no inconsciente do segredo inconfessável de um outro. Sem ter sido jamais consciente, o fantasma seria uma formação do inconsciente resultante da transmissão do inconsciente de um parente ao da criança. Assim se pode notar toda a importância do trabalho com as famílias. Esse trabalho envolve uma investigação sobre o inconsciente dos pais e a elaboração dos elementos transmitidos nessa genealogia dos fantasmas. Eles resultam de coisas ouvidas, experiências vividas e das narrativas dos fatos passados relativos à história dos pais ou dos antepassados.

Provavelmente, não se trata aí senão de uma das pistas que poderiam tentar explicar o que conduziu a paciente a investir (para não dizer se engolfar) nessa relação mortífera. É preciso ser sempre prudente no trabalho da interpretação: o "duplo" e o "duplo-sentido" são velhos cúmplices, como lembra bem Alain de Mijola (1986) quando evoca os processos de identificação nesse livro muito belo que é Les visiteurs du moi.

O trabalho de elaboração deve, então, prosseguir a fim de que Amélie possa tornar-se um indivíduo, um sujeito inteiro, aceder a um processo de subjetivação; para que ela possa, novamente, experimentar o que Winnicott (1969) denominava como continuidade de existir.

\section{REFERÊNCIAS BIBLIOGRÁFICAS}

Abraham, N. (1978). Le travail du fantôme dans l'inconscient. Em Abraham, N. \& Torok, M. L'écorce et le noyau, Anasémies II (pp. 393-474). Paris: Aubier-Flammarion. Aulagnier, P. (1984). Telle une zone sinistrée. Adolescence, no 1, t. 2, 9-21. Mijolla, A. (1986). Les visiteurs du moi. Paris: Les Belles Lettres. 
um bisavô entregue à sua demência, totalmente abandonado pela família que deixava então a África do Norte, com o pouco de bagagem que levavam, pesada de remorsos e de tristeza. Então, que laços estabelecer entre essa culpabilidade inconsciente trazida através de gerações e o sacrifício carregado de reparações a que se entregava Amélie, sob o altar da dívida familiar?

Os fantasmas da identificação são, por definição, inconscientes. A identificação, para Freud, não é, portanto, uma simples imitação, mas antes uma apropriação (Aneignung) sobre a base de uma mesma pretensão etiológica; ela deriva de um elemento comum que persiste no inconsciente (Freud, 1925). Amélie, que não tinha nenhum conhecimento (pelo menos consciente) dessa parte da história familiar, parecia, com efeito, ter efetuado essa "incorporação" inconsciente. Talvez, a sombra desse antepassado voltasse assim, por esse viés, a se perfilar novamente na atualidade familiar. Nicolas Abraham (1978) mostrou que o fantasma é o trabalho no inconsciente do segredo inconfessável de um outro. Sem ter sido jamais consciente, o fantasma seria uma formação do inconsciente resultante da transmissão do inconsciente de um parente ao da criança. Assim se pode notar toda a importância do trabalho com as famílias. Esse trabalho envolve uma investigação sobre o inconsciente dos pais e a elaboração dos elementos transmitidos nessa genealogia dos fantasmas. Eles resultam de coisas ouvidas, experiências vividas e das narrativas dos fatos passados relativos à história dos pais ou dos antepassados.

Provavelmente, não se trata aí senão de uma das pistas que poderiam tentar explicar o que conduziu a paciente a investir (para não dizer se engolfar) nessa relação mortífera. É preciso ser sempre prudente no trabalho da interpretação: o "duplo" e o "duplo-sentido" são velhos cúmplices, como lembra bem Alain de Mijola (1986) quando evoca os processos de identificação nesse livro muito belo que é Les visiteurs du moi.

O trabalho de elaboração deve, então, prosseguir a fim de que Amélie possa tornar-se um indivíduo, um sujeito inteiro, aceder a um processo de subjetivação; para que ela possa, novamente, experimentar o que Winnicott (1969) denominava como continuidade de existir.

\section{REFERÊNCIAS BIBLIOGRÁFICAS}

Abraham, N. (1978). Le travail du fantôme dans l'inconscient. Em Abraham, N. \& Torok, M. L'écorce et le noyau, Anasémies II (pp. 393-474). Paris: Aubier-Flammarion. Aulagnier, P. (1984). Telle une zone sinistrée. Adolescence, no 1, t. 2, 9-21. Mijolla, A. (1986). Les visiteurs du moi. Paris: Les Belles Lettres. 
Freud, S. (1925). Le rêve et son interprétation. Paris: Gallimard.

. (1956). La naissance de la psychanalyse. Paris: PUF.

Green, A. (1990). La folie privée, psychanalyse des cas limites. Paris: Gallimard.

Lauru, D. (2001). Tomber en amour. Toulouse: Erès.

Lesourd, S. (2002). Adolescences... Rencontre du féminin. Paris: Erès.

Rank, O. (1932/1990). Don Juan et son double. Paris: Payot.

Winnicott, D. W. (1969). La capacité d'être seul. Em De la pédiatrie à la psychanalyse (pp. 205-213). Paris: Payot.

Recebido em $1^{\circ}$ de fevereiro de 2007 Aceito para publicação em 27 de agosto de 2007 